\title{
THE SOCIAL WELFARE OF CARDIAC PATIENTS
}

\author{
By D. M. Thornton, M.A.(Oxon.), A.M.I.A. \\ Almoner, The London Hospital
}

The clinical treatment of heart disease cannot be divorced from the everyday life of the patient. Recommendations for adequate rest at home or a suitable occupation are just as necessary as any other form of treatment, and are often much more difficult to obtain. Whilst such aids to diagnosis and treatment as X-rays, electrocardiograms or drugs all have a solid reality, the social welfare work of a cardiac department is intangible and difficult to define. It is also difficult to demonstrate because many patients attend once only for a consultant's opinion and do not come again unless they are referred back by their own doctors. In some cases the social care required by these patients extends beyond their visit to hospital, as in the case of juveniles recommended for vocational training in a suitable occupation, or elderly invalids needing adequate care at home, but the patients do not return and little completed work is ever seen. Lastly, it must be admitted that however keen may be the interest of the cardiologist in the welfare of his patients, in most hospitals the pressure of clinical work is too great to allow for anything but brief reports on a few cases, and it is, therefore, difficult for the doctors to know what happens to patients they refer for help.

In one way the social welfare of patients is a shared responsibility and doctors and nurses and all those who come into personal contact with patients in hospital contribute to it, but constructive case work is very time-consuming, and responsibility for this work usually rests with a hospital almoner.

Since the publication of the report of the Social and Preventative Medicine Committee of the Royal College of Physicians in 1943, much thought has been given to ways in which the medical and social care of patients can be fused into a satisfactory whole. Some physicians consider that a social report should be inserted in the medical notes before the patient is seen by a doctor; others have invited the almoner to be present at ward rounds so that medical and social care can be planned together and both included in the clinical teaching of medical students. While these methods have much to commend them, especially for children, they have two disadvantages for adult patients. The first is that some of the most relevant facts known to the almoner may not be suitable for insertion in the medical notes, neither can they be stated before doctors, nurses, and students at the patient's bedside. Secondly, some patients, in spite of the limitations of their illness, are living well adjusted, normal lives, and do not need the help of an almoner. A more selective method of work means that more time can be given to those patients who are in need of help. Physicians who hold weekly case-conferences at which all their staff are present have often found this a convenient time to consider an almoner's report, or to ask her to contribute, from her knowledge of the patients' home and background, to any plans made for their disposal or future treatment. This method is much more economical in time than a ward round and gives the opportunity for discussion unhampered by the presence of the patient. In different hospitals or in different departments of the same hospital, the formal methods used for blending medical and social work may vary considerably but however excellent they are, it is on the day to day contacts between doctors, nurses and almoner, that the unity of medical and social work depends.

In both wards and clinics the almoner especially dependent on the help of the sisters. I addition to S.O.S. calls, a weekly visit is usualls, paid to the ward at a time when the sister is free to talk over the needs of patients and this consultation prior to seeing the patients themselves is of great value. In the clinics too, the sister is the almoner's ally in discerning the needs of the many patients who pass through her hands. Professor Hobson (1949) has boldly said that "full diagnosis and adequate treatment are impossible without a knowledge of the social and economic factors which influence the life of the patient.' It is certainly true that the basis of any constructive social work must be a personal knowledge of the patient-his home and family, his work, how he spends his leisure, how much economic security he has-and that for cardiac patients this knowledge must be related to their medical treatment.

Medical social work can be divided roughly into two parts:-(i) an attempt to meet the immediate needs of patients, and (ii) long term case work to help them to adapt the rest of their lives to what is usually a progressive illness. Immediate needs take many forms. There are the obvious needs of those seen and diagnosed in the out-patient department and advised by the doctor to go home by car to rest in bed. While arrangements for the car are being made, the almoner has an opportunity to make some enquiry into the circumstances of the patient; to find out, for instance, who will be 
looking after him at home and to arrange help for the mother who asks if the car will be long because the children will be coming home from school and she has her husband's tea to get, or to discuss ways and means with the wife of the patient whose chief concern is ' planting out me new potatoes.' For some patients illness brings financial insecurity, and one of the first needs of a man in the ward is advice about sickness benefit, pension or an application to the Assistance Board for a supplementary allowance, as patients are usually completely ignorant of the statutory provisions made for them. Material needs such as payment of fares, financial help with a special diet, the services of a district nurse, or possibilities for convalescence can be met without difficulty once the need has been recognized. It is always the inarticulate patient who suffers most in a busy outpatient department.

The more difficult side of welfare work is to fulfil the personal needs of patients which cannot be met within the recognized framework of the health service. For example, a young woman, seven months pregnant, was advised by the doctor to give up her work. She then confessed that her earnings were the sole source of income for the family and tearfully produced from her pocket an eviction order for non-payment of rent. Her husband, although unemployed, had failed to present himself at the employment exchange as he was eager to work on his own account as a haulage contractor. It was not until immediate financial help had been received from voluntary sources, her husband had been seen and helped to find permanent work with his lorry, and some provision had been promised to meet the needs of the coming baby, that the 'rest' recommended by the doctor had any reality for the patient.

Sometimes patients' difficulties are not only material but result from emotional stress. One patient, for example, caused the ward sister some concern because she felt that his slow response to treatment was partly due to anxiety and depression. The patient was a wireless officer who had recently returned to England with his wife and two children as a deferred repatriated prisoner of war because, after spending two years in a Japanese internment camp, he had agreed to remain in China to help reestablish communications between the consulate and the outside world. When the patient finally came to England he had visualized a pleasant home, transfer to secure and pensionable employment, and a happy environment for his children. The family were offered accommodation in a Government hostel and provided with an allowance from the Assistance Board, but the husband had been used to a much higher standard of living and was bitterly disillusioned. He was worried because his wife, who had spent all her life in the Far East, quarrelled with his relatives and the strain under which they were living produced a crop of minor ailments in the children. Eventually, with the help of the Welfare Officers of the Ministry of Health and the Foreign Office, a flat of their own was found, financial help from voluntary sources was given to enable them to retrieve their possessions from the Customs, and the patient was offered work within his very limited capacity. Although he remains an invalid, with the relief of emotional stress his mental attitude towards his illness, which he attributed to the hardships of his past and present circumstances, slowly changed and a happier and fuller life became possible for the whole family.

Long-term case work for men with heart disease often centres round their employment. Once the word 'heart' is mentioned, employers are apt to reply, 'You mean he may drop dead at' any moment ?' When, however, with the patient's permission, advice about his work has been conveyed to employers and every effort made to gain their co-operation, many firms show great kindness and consideration to workers with a cardiac disability. Numbers of patients previously engaged in heavy manual labour have been given $Q$ alternative work such as store-keeper, telephone $\delta$ operator, despatch clerk, time-keeper, ticket collector or some form of sedentary bench work, and have remained well and working. Sometimes, however, employers are unwilling or unable to offer alternative work and application is then made to the Disablement Resettlement Officer at the Employment Exchange. This should be the beginning of a partnership between the D.R.O. and the almoner to help and encourage the patient and his family during the difficult days of unemployment, until he is eventually resettled in suitable work. Patients can also be sent, through the Ministry of Labour, for a course of vocational training and although some are deterred by, the long waiting lists, those who have secured vacancies have usually done well. One man, for example, was trained in watch and clock repairing and afterwards placed with a well-known firm. A year later he had begun to build up a small but successful business on his own account. For those whose capacity is too limited for competitive employment, sheltered work in a Remploy Factory may sometimes be the solution. Facilities both for training and for sheltered work are, however, limited and much depends on the goodwill of industry. It would be a fine thing if those firms who used to give so generously to the voluntary hospitals would consider using their funds to provide facilities, possibly on their own premises, for the employment and training of disabled workers. 
In the lives of many patients with heart disease there comes a time when they can either go forward into a life of limited but useful activity, or sink back into invalidism when the words "functional overlay' may be added to a diagnosis of heart disease. Sometimes family doctors who have been glad to receive the help of the cardiologist in diagnosis and treatment hesitate to accept advice about returning a somewhat reluctant patient to work. One man, for example, remained 'on the panel' for seven years although his hobby was gardening. Sprague (1939) says with some truth 'In these practitioners we recognize too commonly an attempt on the part of the doctor to protect himself if the patient suddenly dies, or to attribute himself some virtue in his therapy if the patient does well while suffering from such a serious disease.' Patients may take refuge in functional symptoms when they begin to feel inadequate to face the demands made upon them. Some may be able gradually to make their own adjustments; with others all the encouragement given by the cardiologist is unavailing unless it is supplemented by practical help in adapting their work to their physical limitations.

Although workers with a cardiac disability can usually find employment in heavy manual work without difficulty, they are debarred by a strict medical examination from entering many suitable occupations. It is no uncommon thing for young people at 18 years of age to be dismissed from banks or insurance offices because of a very slight heart lesion, not because they were unable to do the work adequately but because of the superannuation rules governing appointments to the permanent staff. Other workers with a similar disability have been rejected by industrial medical officers for sedentary bench work, or posts as telephone operators or despatch clerks but, driven by financial necessity, have been able to return to such strenuous and hazardous jobs as roof-tiler, river craftsman or timber porter without fear of any medical supervision whatsoever.

The variety of light and often sedentary occupations open to women makes a choice of suitable work much easier for them than for men. It is usually only those needing special encouragement or sheltered conditions who meet with difficulty. The greatest problems are the housewives and mothers whose work it is so difficult to adapt. The first step is to talk over with the patient and her family the practical ways in which more adequate rest can be achieved. For example, the children might have school dinners, so that it is no longer necessary to cook at midday as well as for her husband in the evening; the family washing can be surrendered to the laundry, and arrangements made with local shops for the rations to be called for at a convenient time to avoid queueing. These and other somewhat trivial arrangements may collectively lead to a more restful life for the housewife with heart disease. The Home Help service provided by local authorities is, in most areas, unable to give domestic help which is both adequate and permanent, but after. a period of in-patient treatment, and especially after the birth of a child, a Home Help can do much to safeguard the recovery of the patient during convalescence at home. Bad housing conditions contribute more than anything else to the difficulties of women with heart disease, and numerous certificates are sent to local housing authorities, but the acute shortage of accommodation usually means a long wait even when medical priority has been given. The chronically ill patients, particularly the younger ones, have a special claim on an almoner's help. The provision of such things as an invalid chair, bed rest or air cushion adds to the comfort of the patient at home and, with the help of the local church, youth club or other voluntary organization, it may be possible to arrange for a regular supply of flowers, books and magazines from visitors who bring a breath of the outside world to the home-bound patient. There are also funds available to supply invalids with wireless sets and to keep these in good repair, and societies' such as the British Red Crosso supply handicrafts of all kinds. Some patients may be able to earn a little pocket money byo making such articles as gloves or soft toys, and the advice of the occupational therapist has proved invaluable.

The after care of children and young people attending a cardiac department is perhaps the most interesting and rewarding part of the almoner's work. No one who has read the joint report of the Cardiac Society and the Pediactric Association on the Care of Rheumatic Children (1944) can fail to be impressed by its insistence on the importance of their social welfare. This has further been emphasized by Sir John Parkinson (1945) who has described rheumatic fever as " the dominating cause of heart disease under the age of 40 , and the source of almost 40 per cent. of heart disease in hospital. No other disease has so clear a social incidence.' One of the first duties of the almoner is to keep in touch with the children referred to the cardiologist following an attack of rheumatic fever and to ensure that they attend regularly for re-examination until they can either be reassured that their hearts are healthy or their cardiac disability can be assessed and plans made for their future. Visits to the homes of the children have shown how adverse are the conditions under which some of them live. With the support of the health visitor, urgent representations are made to local authorities for re-housing, 
but in some ro per cent. of cases the evidence of a dirty home, fly-blown food and lack of personal hygiene make the removal of the child to a residential school or training centre the only solution. Very few parents would knowingly neglect their children but some adopt a curiously detached attitude towards them once they have left school and it is quite common to hear the parents of a I 5-year-old boy say that they will not 'interfere' and he 'must decide for himself,' about his attendance at hospital or choice of a career. Many parents are, however, only too glad to have the benefit of accurate diagnosis combined with early and adequate treatment and co-operate to the full in any recommendations made by the cardiologist. Occasionally, children who fail to attend for re-examination are found in the chronic wards of local hospitals following a recurrence of their illness. Whenever possible, arrangements are made for their transfer to hospital schools where specialized treatment can be combined with education.

The adult patient who has been recommended for a sedentary occupation, but describes himself as ' no scholar,' is difficult to place in suitable work. It is, therefore, of the greatest importance that contact should be made with school teachers and education authorities to ensure that the children are not handicapped by lack of education as well as by a cardiac disability.

Some children described as 'too ill' to go to school have been known to make speedy recoveries when they reach school-leaving age, and it is clear that the rest originally recommended by their family doctors has been unnecessarily prolonged by over-anxious parents or reluctant scholars. Because of their low educational standard these children tend either to drift into unskilled manual work or to remain indefinitely at home. It is most important that all children with a cardiac disability should be seen and assessed by a cardiologist during their school-leaving year and every effort made to ensure that his advice about their future is followed. Children at secondary or grammar schools can usually pass on without difficulty to a suitable career. Juveniles leaving school at 15 years have more difficulty, for although there may be a variety of repetitive unskilled work available to them, this not only fails to satisfy the more intelligent boy or girl but gives them no security for the future and all too often at 18 years of age they are either unemployed or attracted by higher wages and better prospects to unsuitable work. The old form of apprenticeship is fast dying out, but some firms are prepared-to offer juveniles progressive posts which combine practical and technical instruction. For other children application is made to educational authorities or through the Juvenile Advisory Committees of the Ministry of Labour for training in such subjects as draughtsmanship, leather work, watch and clock repairing, fine needlework, book-keeping, accountancy and clerical work of all kinds. Vocational training for these patients has a double value; not only does it equip them to earn their own living in work which is suited to their cardiac disability, but many of them find new confidence and independence as a more purposeful life becomes possible for them. One boy, for example, who had had no schooling since the age of 12, began work as a paper boy because, his parents explained in his presence, ' he will never be like other boys.' A vacancy was eventually secured for him at a training centre where, after some of the defects in his education had been made good, he was trained as a draughtsman and later placed with an engineering firm. One intelligent girl of 15 years had never been to school when first seen, but after three years of individual tuition at a special school she later qualified as a nursery school teacher. Much can sometimes be achieved even for children who are too severely handicapped for normal employment. For example, one girl aged i 5 years, suffering from severe congenital heart disease for which no operative treatment could be advised was described by the doctor who referred her to hospital as ' mentally deficient' but she was in fact only backward because of lack of education. The girl had no contacts outside her own home and did not possess a wireless set. She responded well to occupational therapy and, at the hospital's request, the Education Committee agreed to provide a home tutor and a portable wireless. In view of her need for young companionship she was enrolled as a Lone Guide and adopted by a local company. Within a year she has not only found new interest, and enjoyment in life but has begun to make a small income by weaving and soft-toy making at home.

It would be wrong to claim a full measure of success for all the after-care work of children with cardiac disability. During adolescence some are headstrong, wilful and unreconciled to their physical limitations whilst a few retreat too easily into invalidism.

Whilst the social care of adult patients with established heart disease can seldom be more than palliative, the emphasis of the work for many of the younger patients is in preventive medicine.

\section{BIBLIOGRAPHY}

Cardiac Society and Pediactric Association Report on the Care of Rheumatic Children (1944), British Heart fournal, 6, 99.

HOBSON, W. (1949), Brit. Med. F., 2, 125

PARKINSON, J. (1945), Lancet, 2, 657.

SPRAGUE, H. (1939), Ұ. Amer. Med. Ass., I12, 2384. 